\title{
Radiology Toolbox Pro App Review
}

\author{
George Rahmani ${ }^{1}$ (C)
}

Published online: 21 June 2017

(C) Society for Imaging Informatics in Medicine 2017

\section{App Specs}

App Name: Radiology Toolbox Pro

App Icon URL: https://itunes.apple.com/us/app/ radiology-toolbox-pro/id466281848? $\mathrm{mt}=8$

App Developer: Eric M. Baumel, MD and Softcode Systems, Inc.

App Developer Website: https://www.softcode.com/

App Price: \$3.99 for Pro version. A free "Lite" version also exists

Apple App Store URL: https://itunes.apple.com/us/ app/radiology-toolbox-pro/id466281848?mt=8

Google Play Store URL: Currently only available on iOS

Category: learning, radiological guidelines, calculator

Tags: radiology, iPad-compatible, guidelines

Works Offline: Yes

FDA Approval: N/A

Quick Review (1 star, lowest; 5 stars, highest)

Overall Rating (1-5): 4

Content (1-5): 4

Usability (1-5): 5

George Rahmani

george.rahmani@gmail.com

1 Galway University Hospitals, Galway, Ireland
Pros: Easy access to useful and frequently called upon information. Simple menu with nice graphics.

Cons: Currently only available on iOS.

At a glance: This app provides easy access to information that most radiologists find themselves looking up several times throughout the day. It includes calculators, anatomy diagrams, diagnostic guidelines, followup guidelines and contrast dye information

\section{Introduction}

Radiology Toolbox Pro was developed with the everyday radiologist in mind. It provides relevant information for X-ray, CT, MRI, ultrasound and nuclear medicine. This app was developed by Eric Baumel, a Floridabased radiologist who like many found himself looking up the same information several times throughout the day. It provides easy access to useful information including calculators, anatomy diagrams, diagnostic guidelines as well as guidelines on the follow-up of indeterminate lesions.

\section{Purpose/Features/Content}

The main purpose of the app is to have information that is commonly searched by the everyday radiologist 


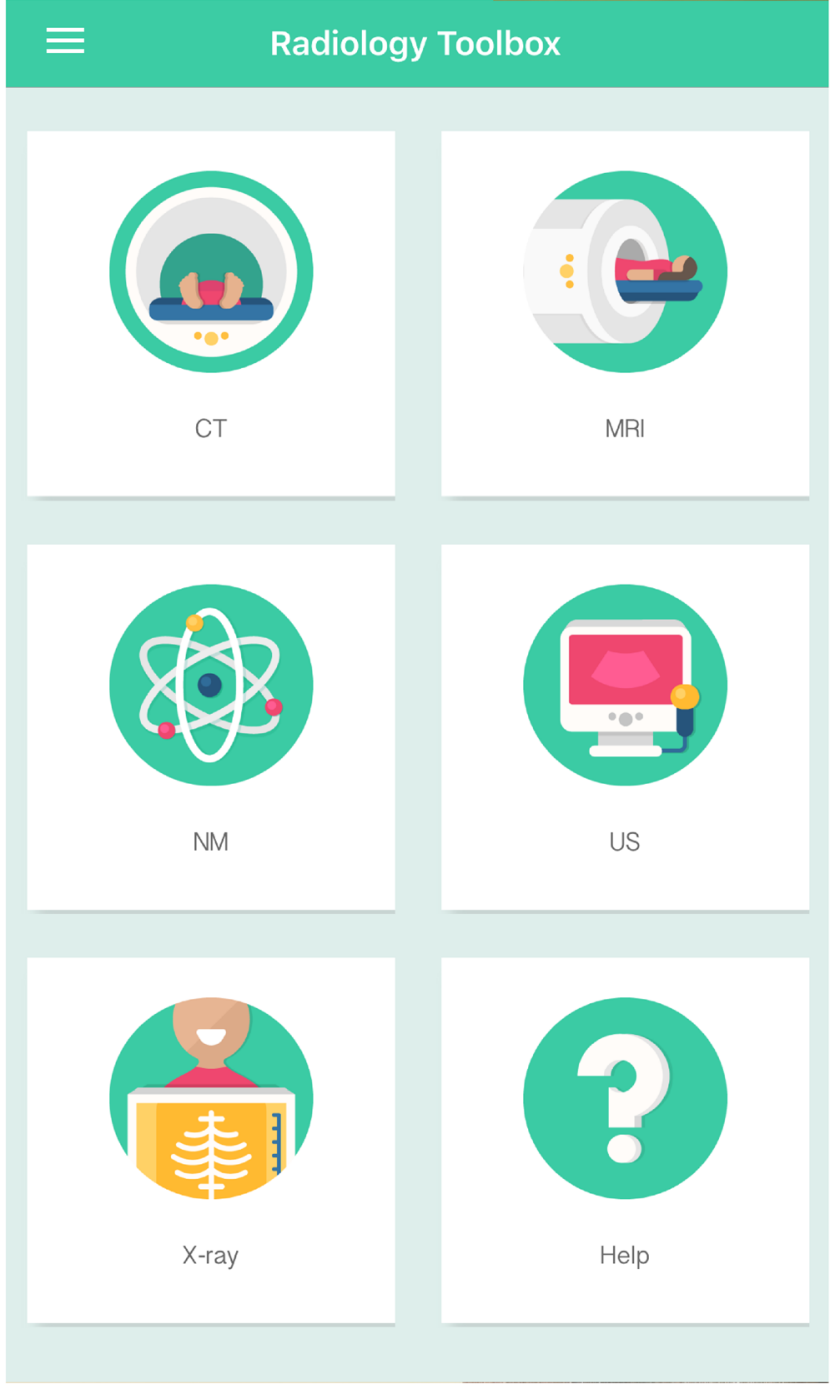

Fig. 1 The main menu screen

readily available at their fingertips thereby making their day-to-day practice more efficient. The app is available offline which means that the information is always available when needed.

Once the app is opened, users are greeted by a home menu with simple and attractive icons (Fig. 1). Each modality has a separate section and is depicted by its own cartoon graphic. These graphics are also available to download for use as emojis using the 'Radiology Stickers' app.
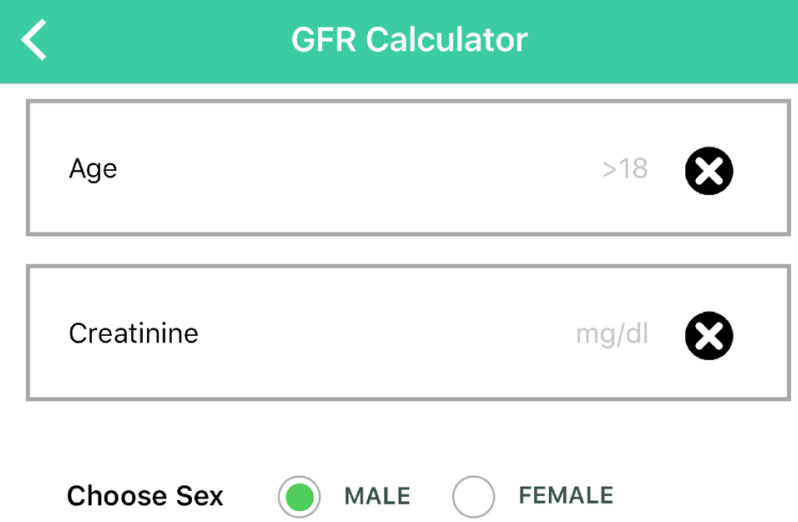
Choose Race
BLACK
OTHER

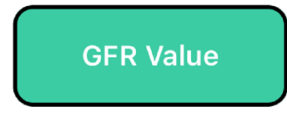

Calculate

Fig. 2 GFR calculator

Some examples of useful features to highlight include a glomerular filtration rate (GFR) calculator that estimates GFR based on age, creatinine, sex and race (Fig. 2). A table providing information on the upper limits of normal-sized lymph nodes throughout the body was also particularly useful (Fig. 3) as well as the 2017 Fleischner Society guidelines on pulmonary nodule follow-up (Fig. 4) [1]. There are diagrams depicting the Salter Harris classification of fractures involving the epiphyseal plate found in the $\mathrm{X}$-ray section (Fig. 5) [2], and extensor compartments of the wrist found in the MRI section (Fig. 6).

\section{Usability}

The app is easy to use with a simple layout. There is a separate section that provides information specific to 
Lymph Node Size

\section{Lymph Node Size}

\section{Short axis diameter upper limits of normal.}

\begin{tabular}{|l|r|}
\hline \multicolumn{1}{|c|}{ Region } & Size \\
\hline Most cervical nodes & $\begin{array}{r}10 \\
\mathrm{~mm}\end{array}$ \\
\hline Submental \& submandibular & $\begin{array}{r}15 \\
\mathrm{~mm}\end{array}$ \\
\hline Retropharyngeal & $\begin{array}{r}8 \\
\mathrm{~mm}\end{array}$ \\
\hline $\begin{array}{l}\text { Axillary } \\
\text { Paratracheal, hilar, } \\
\text { subcarinal, paraesophageal, } \\
\text { paraaortic, or subaortic } \\
\text { region }\end{array}$ & $\begin{array}{r}10 \\
\mathrm{~mm}\end{array}$ \\
\hline $\begin{array}{l}\text { Peridiaphragmatic region } \\
\text { mm }\end{array}$ & $\begin{array}{r}5 \\
\text { mm }\end{array}$ \\
\hline
\end{tabular}

Fig. 3 Upper limit of lymph node size

each modality. There is a sidebar menu allowing easy transition from one section to another. The diagrams and tables in the app are high-resolution images that are amenable to 'pinch-to-zoom' making it easy to view.

\section{Good}

The app works well both on iPhone and iPad. Each section also has a 'suggestions' tab where users are invited to email
Pulmonary Nodule

\section{Pulmonary Nodule}

\author{
2017 Fleischner Society Guidelines
}

\section{Solitary}

\begin{tabular}{|l|l|l|}
$\begin{array}{c}\text { Nodule } \\
\text { size } \\
(\mathrm{mm})\end{array}$ & $\begin{array}{l}\text { Low-Risk } \\
\text { Patient }\end{array}$ & $\begin{array}{c}\text { High-Risk } \\
\text { Patient }\end{array}$ \\
\hline$<6$ & $\begin{array}{l}\text { No F/U } \\
\text { needed }\end{array}$ & $\begin{array}{l}\text { Optional CT } \\
\text { @ } 12 \\
\text { months }\end{array}$ \\
\hline $6-8$ & $\begin{array}{l}\text { F/U CT at } \\
6-12 \text { mo, } \\
\text { then } \\
\text { consider } \\
18-24 \text { mo }\end{array}$ & $\begin{array}{l}\text { Inital F/U CT } \\
\text { at } 6-12 \text { mo, } \\
\text { then @ 18- } \\
24 \text { mo if N/C }\end{array}$ \\
\hline$>8$ & $\begin{array}{l}\text { F/U CT at } \\
\text { 3 mo } \\
\text { and/or } \\
\text { PET/CT, } \\
\text { and/or } \\
\text { Biopsy }\end{array}$ & $\begin{array}{l}\text { Same as for } \\
\text { low risk } \\
\text { patient }\end{array}$ \\
\hline
\end{tabular}

Fig. 4 Table adapted from the 2017 Fleischner Society guidelines on pulmonary nodule follow-up

ideas and suggestions to the app developers. There is also a short account of Wilhelm Röntgen's work in 1895 which is a nice touch.

\section{Room for Improvement}

Some of the tables relating to guidelines are quite large and require the user to scroll down and/or zoom out to read each row. A section on radiation doses of each imaging study 


\section{Salter Fracture Types}

Salter-Harris Fractures

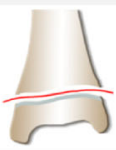

Salter 1

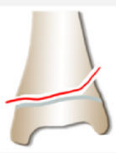

Salter 2

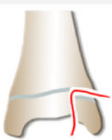

Salter 3

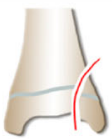

Salter 4

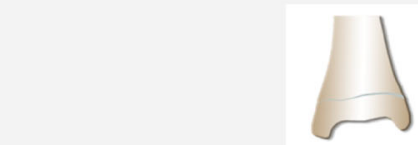

Salter 5

Salter RB, Harris WR. Injuries Involving the Epiphyseal Plate. J Bone Joint Surg Am $1963: 45(3): 587-622$

Fig. 5 Salter Harris classification of fractures involving epiphyseal plates

would be a nice addition as well as a 'favourites' section to store information that the user uses most often. At present, the app is only available on iOS, limiting it to iPhone and iPad users. It would be nice to develop the app for use with Android devices.

\section{References}

1. MacMahon H, Naidich DP, Goo JM, Lee KS, Leung AN, Mayo JR, et al.: Guidelines for Management of Incidental Pulmonary Nodules
Wrist Tendon Compartments

\section{Wrist Tendon \\ Compartments}

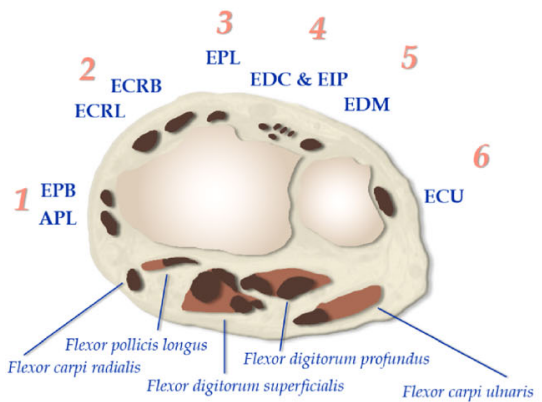

\begin{tabular}{|l|l|}
\hline Compartment & \multicolumn{1}{|c}{ Tendons } \\
\hline 1 & $\begin{array}{l}\text { Abductor pollicis } \\
\text { longus (APL) and } \\
\text { Extensor pollicis } \\
\text { brevis (EPB) }\end{array}$ \\
\hline
\end{tabular}

2

\section{Extensor carpi radialis longus (ECRL) and Extensor carpi radialis brevis}

Fig. 6 Diagram outlining the extensor compartments of the wrist

Detected on CT Images: From the Fleischner Society 2017. Radiology 161659, 2017

2. Salter R, Harris W: Injuries involving the epiphyseal plate. J Bone Joint Surg Am. 45(3):587-622, 1963 